\title{
A Brief Review on Dementia from a Psychological Perspective
}

\author{
J. Henriques-Calado and M. E. Duarte-Silva
}

\begin{abstract}
A brief literature review of dementia and its psychological concerns is presented. Early diagnosis, risk factors, associated personality and psychopathology are discussed, with the focus being on the contribution of the personality perspective to the understanding of this disease. While recognizing undoubtedly its organic character, dementia is considered to be a clinical syndrome, with factors of personality organization being identified as fundamental. Neurological/organic diseases also illustrate the interaction of the brain and mind, as exemplified by Alzheimer's disease. Dementia showing the complex interrelations between the different bio-psycho-social aspects of the human being experience.
\end{abstract}

Index Terms-Aging; Alzheimer's Disease; Dementia; Personality; Clinical Psychology.

\section{INTRODUCTION}

A number of genetic, medical, psychological, and social factors have been linked to Alzheimer's disease. Among the psychological factors there has been some interest in the role of personality related to individuals' lifestyles. The personality has implications in physical and mental health, including the risk of Alzheimer's disease, with effect sizes similar to those of well-established clinical and lifestyle risk factors [1].

\section{OBJECTIVE}

A brief review of the literature on dementia and its psychological concerns from the point of view of the personality theme.

\section{MATERIALS AND METHODS}

A review of the literature was obtained by using databases EBSCO / Web of Knowledge / Medline / Pubmed, using different combinations of the keywords "Alzheimer's disease", "dementia", "psychological perspective", "personality" "psychopathology", and "psychodynamic", published between 1985 and 2017.

\section{RESUlTS AND DisCUSSION}

80 global references were obtained, and 36 references were considered relevant on the personality approach of dementia.

Manuscript received August 16, 2017.

J. Henriques-Calado, Universidade de Lisboa, Faculdade de Psicologia, Alameda da Universidade 1649-013 Lisboa, Portugal (e-mail: jhcalado@psicologia.ulisboa.pt ; joanahenriquescalado@gmail).

M. E. Duarte-Silva, Universidade de Lisboa, Faculdade de Psicologia, Alameda da Universidade 1649-013 Lisboa, Portugal (e-mail: meduartesilva@psicologia.ulisboa.pt).

\section{A. Framework}

The classical tendency to consider neurological disturbances as 'organic' and psychiatric disturbances as 'functional' has been the cause of innumerous debates over the years [2]. An extensive superposition of causes, symptoms, and disturbance treatments provide a set of evidence, which, considered simultaneously as neurological and psychological, will reveal a better and more truthful understanding of these pathologies [3].

Many authors recognize the complex interconnection between cognitive and emotional deficits, organic and emotional disturbances, brain and mind operation. It is not only that the brain influences the mind, but also that the mind influences the brain [4], [5]. Some studies show that it is possible for aging to progress healthily, even in cases of brain pathology. People who in life remained cognitively and mentally intact can present evidence of a neurodegenerative pathology in a post-mortem examination, achieving resistance to the disease through unknown mechanisms [2]. Other people may display symptoms recognizable as Alzheimer's disease, while their post-mortem examination does not present evidence of a neurodegenerative pathology [6]. Some authors even raise the question "Is neurological damage a cause or an effect of dementia?" [7].

Apart from the traditional organic model, a literature survey by [8] presents other possible explanations for symptoms of dementia: disability, deviation from social norms, major functional disturbance, psychosis, descent into a subjective state, regression, exhibition of grief for losses and trauma (post-traumatic state).

The work by [9] perceives dementia as a senile psychosis, a premature traumatic experience, manifesting itself particularly in the expression of the personality, with people being prone to the development of dementia in advanced adult age [9]. In this perspective, the neurological deficits are potentiated by the psychological factors [9], [10].

\section{B. Early diagnosis and risk factors}

There is strong interest in diagnosing Alzheimer's disease in its initial phase, currently considered to be one of the primary focal points for research. An early diagnosis is critical for the clinical staff, the family and the person himself, helping to plan the control of the disease both in terms of medication and psychological and social intervention [11], [12]. Some researchers advocate that changes in personality may potentially precede the cognitive changes that typically signal the diagnosis 
of Alzheimer's. The predictive power of personality traits may help mark the beginning of dementia; the personality assessment may discriminate between a healthy aging and the early onset of dementia. It is of the utmost importance that, in the future, a personality assessment is included in the diagnosis process for Alzheimer's disease [11], [13], [14].

Major risk factors reside in people with depression or a family history of dementia, which are statistically seven times more likely to suffer from dementia [15]. In a study by [13], it is stressed that patients with next of kin with dementia show characteristics of atypical depression, the majority of them presenting a diagnosis of borderline personality. It seems that there is evidence of an association between atypical depression characteristics, personality traits, psychological stressors and a family history of dementia. In fact, factors such as depression and anxiety seem to play a role in the pathogenesis of dementia, particular of the type associated with Alzheimer's [8], [15], [16], with atypical depression being closely associated with dementia [13].

Some authors consider that depression may be a first symptom of dementia, but it is not known how far this functional disturbance increases the tendency of the individual to express his dementia, or even if indeed depression is the first symptom of dementia [13]. A study of note here, revealed the discovery of senile plates in the locus coeruleus in patients with Alzheimer's disease, similar to those found in young depressed patients who committed suicide [17]. For some researchers, depression symptoms may be used as early indicators of the onset of Alzheimer's, instead of being considered a consequence of dementia, and may be connected to the neuropathology underlying the process. Some other authors propose a more complex framework for this pathology, with the first manifestation of symptoms occurring at a younger age and suggesting that these symptoms are more affective than cognitive [11]. The atypical depression seems to be intimately related with personality disorders, as well as with traumatic life events [13]. On the other hand, the personality disorders are connected with the occurrence of depression in old age. Patients with an early onset of depression more frequently show personality disorders (avoidant and dependent) when compared with those that exhibit depression later in life [18].

\section{Personality and psychopathology}

Changes in personality have been documented in the literature for individuals with a diagnosis of Alzheimer's disease [19], [20], [21], [22]. One fact seems to transverse different studies and garner unanimity between researchers: when compared with healthy elderly people, those suffering from the initial and moderate states of dementia show an increased level of neuroticism and a decreased level of conscientiousness, based on both the self-reported and informant versions of the NEO-PI measures [21], [23]. It seems that a link exists between a tendency for neuroticism and an increased risk of Alzheimer's disease [14], [24]. Individuals with higher levels of neuroticism are twice as likely to the develop Alzheimer's than individuals with lower levels of neuroticism [14]. Some argue that psychopathological symptoms may reflect an exaggeration or a morbid distortion of behavioral tendencies accumulated over a lifetime, possibly being intensifications of already existing traits [24], [25].

From a nosological point of view, personality disorders and emotional functioning are essential for most organic based diagnoses, as described in DSM classification of neurological diseases [26]. A study by [27] has evaluated the role of personality disorders in the occurrence of dementia. Semi-structured interviews administered to participants in accordance with DSM-IV were used to classify patients regarding the presence of personality disorders prior to suffering from dementia. Results revealed that $67 \%$ of patients showed prior personality disorders, mainly belonging to clusters $\mathrm{B}$ and $\mathrm{C}$; patients assessed as belonging to cluster A revealed more traits of delirium and anger, while patients of clusters B and $\mathrm{C}$ showed more eating disorders, fragile self-esteem, separation anxiety, need for attachment and depressive symptoms related to separation and losses. According to [27], the analysis of the psychological and behavioral clusters in dementia can be seen to be essential to the understanding of neurodegenerative pathologies. The study proposes a psychodynamic approach, stressing the influence of the pre-morbid personality on the display of the dementia framework, as the nature of this symptomatology seems to be influenced by the previous personality. It is important to establish a link between certain childhood life events, during a period of mental structuring and organization, and other situations that may occur over the life cycle, when separations and losses are going to test individual abilities based on the capacity to reaffirm a depressive position [28].

\section{The psychodynamic perspective}

Only a few psychodynamically oriented works have been produced in order to understand the disturbed states of the elderly person [5], [6], [29]. Psychoanalytical psychology addresses this phase of life, mainly, exploring how the individual faces loss and, ultimately, death, with this being related to the ability required early on to deal with the psychic reality [5], [6]. Although psychoanalytical psychology has not yet explored in detail some aspects of neurodegenerative diseases, many phenomena related with mental and affective states of individuals with dementia may be understood and integrated in psychoanalytical terms. The idea of understanding the organic pathology through the psychoanalytical psychology is not recent, despite being uncommon [5], [6].

The majority of the psychodynamic authors who study this problem assume a pre-morbid personality of a limit organization, through its anaclitic object relation, and not excluding the existence of late traumatic memories [7], [30], [31], [32], [33]. Such risk factors, experienced as early trauma, may cause continued stress reactions throughout the life cycle. Associations between this phenomenon and the early and pathologic mental aging have been established [14], [34]. 


\section{CONCLUSION}

Some researchers consider that demented patients retain many of their former personalities. The personality changes, which appear with the evolution of disease, are interpreted as accentuations of premorbid personality traits [22], [35].

A better understanding of personality organization on disease susceptibility and risk, or the interaction between personality change and the disease process, may permit both early detection of Alzheimer disease and a more appropriate care [1], [3], [35].

Dementia, as exemplified by Alzheimer's disease being considered the typical neurological disease, seem to illustrate the interaction between brain and mind, exemplified by the complex relationships between the various bio-psycho-social aspects of the human being experience. Genetics, the location and extent of brain damage, motives and drives, individual history, previous structure of personality and attachment style, combine and coalesce to influence the idiosyncratic presentation of dementia in an individual [3], [36].

\section{REFERENCES}

[1] Terracciano, A., Sutin, A. R., An, Y., O'Brien, R. J., Ferrucci, L., Zonderman, A. B., \& Resnick, S. M. (2014). Personality and risk of Alzheimer's disease: New data and meta-analysis. Alzheimer's \& Dementia, 10(2), 179-186. doi: 10.1016/j.jalz.2013.03.002

[2] Steen, R. G. (2007). The evolving brain: The known and the unknown. New York: Prometheus Books.

[3] Downs, M., Clare, L., \& Anderson, E. (2008). Dementia as a biopsychosocial condition: Implications for practice and research. In B. Woods \& L. Clare (Eds.), Handbook of the clinical psychology of ageing (pp. 145-160). London: Wiley.

[4] Schore, A. N. (2001). The effects of a secure attachment relationship on right brain development, affect regulation, and infant mental health. Infant Mental Health Journal, 22, 7-66. doi: 10.1002/ 1097-0355(200101/04)22

[5] Waddell, M. (2007). Only connect: The links between early and later life. In R. Davenhill (Ed.), Looking into later life: A psychoanalytic approach to depression and dementia in old age (pp. 187-200). United Kingdom: Karnac.

[6] Evans, S. (2008). Beyond forgetfulness: How psychoanalytic ideas can help us to understand the experience of patients with dementia. Psychoanalytic Psychotherapy, 22(3), 155-176.

[7] Chevance, A. (2005). Désir d'oubli chez le patient alzheimer, un concept clef pour une prise en charge psychothérapique [Wish of neglect at the alzheimer patient, a key concept for a psychotherapeutic change]. In J. M. Talpin (Ed.), Cinq paradigmes cliniques du vieillissement (pp. 107-146). Paris: Dunod.

[8] Cheston, R., \& Bender, M. (1999). Understanding dementia: The man with the worried eyes. United Kingdom: Kingsley.

[9] Kitwood, T. (1997). Dementia reconsidered: The person comes first. United Kingdom: Open University Press.

[10] Baldwin, C., \& Capstick, A. (2007). Tom Kitwood on dementia: A reader and critical commentary. London: McGraw-Hill.

[11] Duchek, J., Balota, A., Storandt, M., \& Larsen, R. (2007). The power of personality in discriminating between healthy aging and early stage alzheimer's disease. Journal of Gerontology, 62(6), 353-361. doi: $10.4061 / 2010 / 417615$

[12] Kunik, M. E., Martinez, M., Snow, A. L., Beck, C. K., Cody, M., Rapp, C. G., Molinari, V. A., Orengo, C. A., \& Hamilton, J. D. (2003). Determinants of behavioral symptoms in dementia patients. Clinical Gerontologist, 26(3-4), 83-89. doi: 10.1300/J018v26n03_07

[13] Fountoulakis, K. N., Tsolaki, M., \& Kazis, S. (2001). Investigation of borderline dementia, particularly of alzheimer's type, compared with non-demented patients with similar neuropsychological profiles. International Journal of Psychiatry in Clinical Practice, 5, 55-61. doi: $10.1080 / 136515001300225204$
[14] Wilson, R. S., Evans, D. A., Bienias, J. L., Mendes de Leon, C. F., Schneider, J. A., \& Bennett, D. A. (2003). Proneness to psychological distress is associated with risk of Alzheimer's disease. Neurology, 61, 1479-1485. doi: 10.1212/01.WNL.0000096167.56734.59

[15] Shalat, S., Seltzer, B., Pidcock, C., \& Baker, E. (1987). Risk factor for Alzheimer's disease: A case control study. Neurology, 37, 1630-1637. doi: 10.1002/ana.410330306

[16] Miller, E., \& Morris, R. (1993). The psychology of dementia. New York: Wiley.

[17] Isidoridou, M. R., Havaki, S., \& Chrysanthou-Piterou, M. (1997). Senile plaques in the locus coeruleus of young depressives: Localization with and electron microscopical method. Psychiatriki, 6, 365-71.

[18] Nubukpo, P., Hartmann, J., \& Clément, J. P. (2005). Rôle de la personnalité dans la dépression du sujet âgé: Difference entre dépression avec ou sans antécédents [Role of personality in depression of the elderly: Difference between early and late life depression]. Psychologie et NeuroPsychiatrie du Vieillissement, 3(1), 63-69. doi: 10.1051/medsci/ 20052110811

[19] Strauss, M., Pasupathi, M., \& Chatterjee, A. (1993). Concordance between observers in descriptions of personality change in alzheimer's disease. Psychology and Aging, 8(4), 475-480. doi: 10.1037/0882-7974.8.4.475

[20] Siegler, I., Dawson, D., \& Welsh, D. (1994). Caregiver ratings of personality change in alzheimer disease patients: A replication. Psychology and Aging, 9(3), 464-466. doi: 10.1037/0882-7974.9

[21] Robins-Wahlin, T. B., \& Byrne, G. J. (2011). Personality changes in Alzheimer's disease: a systematic review. International Journal of Geriatric Psychiatry, 26(10), 1019-1029. doi: 10.1002/gps.2655

[22] Henriques-Calado, J., Duarte-Silva, M. E., \& Sousa Ferreira, A. (2016). Personality traits in women with Alzheimer's disease: Comparisons with control groups with the NEO-FFI. Personality and Individual Differences, 101, 341-347. doi: 10.1016/j.paid.2016.06.024

[23] von Gunten, A., Pocnet, C., \& Rossier, J. (2009). The impact of personality characteristics on the clinical expression in neurodegenerative disorders: A review. Brain Research Bulletin, 80(4), 179-191. doi: 10.1016/j.brainresbull.2009.07.004

[24] Chatterjee, A. (1992). Personality changes in Alzheimer's disease. Archives of Neurology, 49, 486-491.

[25] Brandt, J., Campodonico, J., Rich, J., Baker, L., Steele, C., Ruff, T., Baker, A., \& Lyketsos, C. (1998). Adjustment to residential placement in alzheimer disease patients: Does premorbid personality matter?. International Journal of Geriatric Psychiatry, 13, 509-515. doi: 10.1002/(SICI)1099-1166(199808)13:83.3

[26] Trull, T., \& Widiger, T. (2003). Personality disorders. In J. Graham \& J. Naglieri (Eds.), Handbook of psychology: Clinical psychology (pp. 149-172). U.S.A.: Wiley \& Sons.

[27] Auguste, N., Federico, D., Dorey, J. M., Sagne, A., Thomas-Antérion, C., Rouch, I., Laurent, B., Gonthier, R., \& Girtanner, C. (2006). Particularités sémiologiques des synptômes comportamentaux et psycholoqiques de la démence en fonction de la personalité antérieure, de lénvironnement familial et de la sévérité de la démence [Role of personality, familial environment, and severity of the disease on the behavioral and psychological symptoms of dementia]. Psychologie et NeuroPsychiatrie du Vieillissement, 4(3), 227-235. doi: 10.1684/pnv.2009.0195

[28] Coureau-Guillier, S., \& Villerbu, L. M. (2006). Facteurs psychoaffectifs de la démence: $\mathrm{D}$ une hypothétique psychogenèse de la démence : Revue dês théories actuelles. [Psychoaffective factors of dementia: Of a putative psychogenesis of dementia: Review of current theories]. $\begin{array}{llll}\text { Neurologie-Psychiatrie-Gériatrie, } & 6(35), & 29-35 . & \text { doi: }\end{array}$ -10-2006-6-35-1627-4830-101019-200609460

[29] Balfour, A. (2007). Facts, phenomenology, and psychoanalytic contributions to dementia care. In R. Davenhill (Ed.), Looking into later life: A psychoanalytic approach to depression and dementia in old age (pp. 222-247). United Kingdom: Karnac.

[30] Abraham, V. G., \& Walter, M. (2008). À propos d’une psychopathologie de la démence [On psychopathology of dementia]. NPG Neurologie-Psychiatrie-Gériatrie, $\quad 47, \quad 32-37 . \quad$ doi: 10.1016/j.npg.2008.01.018

[31] Gerardin, P., \& Maheut-Bosser, A. (1998). En partance, ou à la recherche de soi [Wandering]. La Revue Française de Psychiatrie et de Psychologie Médicale, 20, 52-53. 
[32] Myslinski, M. (1998). L`attachment thérapeutique : Une réponse humaine à la souffrance de l’abandon dans la démence [Therapeutic attachment: $\mathrm{A}$ human response to suffering in dementia]. La Revue Française de Psychiatrie et de Psychologie Médicale, 20, 46-47.

[33] Henriques-Calado, J., Duarte-Silva, M. E., \& Sousa Ferreira, A. (2017). Anaclitic personality dimension in women with Alzheimer's disease: Comparison with control groups. Personality and Individual Differences, 109, 166-171. doi: 10.1016/j.paid.2017.01.001

[34] Wilson, R. S., Arnold, S. E., Schneider, J. A., Kelly, J. F., Tang, Y., \& Bennett, D. A. (2006). Chronic psychological distress and risk of Alzheimer's disease in old age. Neuroepidemiology, 27, 143-153. doi: 10.1159/000095761

[35] Pocnet, C., Rossier, J., Antonietti, J., \& von Gunten, A. (2012). Personality traits and behavioral and psychological symptoms in patients at an early stage of Alzheimer's disease. International Journal of Geriatric Psychiatry, doi: 10.1002/gpd.3822

[36] Garner, J. (2004). Dementia. In S. Evans \& J. Garner (Eds.), Talking over the years: A handbook of dynamic psychotherapy with older adults (pp. 215-230). U.S.A.: Brunner-Routledge. 